\title{
https://doi.org/10.46813/2021-134-162 \\ CONTRIBUTION OF DRIFT AND DIFFUSION TO WATER CAPACITY DEIONIZATION
}

\section{D.V. Kudin, V.M. Ostroushko, A.V. Pashchenko, S.V. Rodionov, M.O. Yegorov, L.M. Zavada National Science Center "Kharkov Institute of Physics and Technology", Kharkiv, Ukraine E-mail: ostroushko-v@kipt.kharkov.ua}

Drift and diffusion of ions in a cavity having the shape of oblate ellipsoid of revolution are considered. The obtained approximate relationship, between the time of drift and diffusion filling of deep cavity with ions, contains the applied voltage and the ratio of cavity size to the distance between electrodes. It shows that in the performed experiments with the device for water capacitive deionization the filling of electrodes by ions was carried out, mainly, due to diffusion.

PACS: $82.47 . \mathrm{Uv}$

\section{INTRODUCTION}

Capacitive deionization is one of the ways to reduce a salt concentration in water. In contrast to the methods, in which all salt water is pumped through filters (pressure-driven membrane processes), in capacitive deionization, mainly, dissolved salt ions are drawn inside the porous electrodes (for the following removing away), whereas a flow of salt water passes by electrodes, and the role of the filter, with respect to the flow, to a certain extent, in a certain sense, is played by the electric field transverse to the flow, which does not require additional pressure to pump the flow.

At present, various studies of the processes that take place in devices for water capacitive deionization have been performed. In [1 - 3], the characteristics of the device based on carbon material SAUT-1S are studied when working with water containing salts of $\mathrm{NaCl}$ and $\mathrm{NaNO}_{3}$. In [4], the characteristics of the equilibrium state are experimentally investigated (in particular, the value of the amount of adsorbed substance in the electrodes, achievable for solutions with different contents of different salts under the long-time use of different voltage is measured) and the theoretical model is developed, which describes the process with use of small number of thermodynamic parameters related to the electrical double layers in the cavities inside the electrodes.

An important characteristic of devices for water capacitive deionization is the time of filling the cavities in the electrodes with ions formed due to the dissociation of salt molecules in aqueous solution, and the time of release of cavities from ions. This time is determined by ion drift in the electric field and diffusion, and depends on the shape of the cavities, in particular, on the ratio of the cavity depth to the outlet size. In the present work, to estimate the dependence parameters, it is considered a cavity that has the shape of oblate ellipsoid of revolution, for which the drift and diffusion problems can be solved by the method of separation of variables.

\section{DRIFT}

The descriptions of ion drift into and out of the cavity in the given stationary field may be obtained from each other by change of time direction. The characteristic time of entrance or exit is determined by the field strength distribution. It may be obtained from the
Laplace equation for the potential, $\nabla^{2} \Phi=0$, in which $\Phi=S(\sigma) T(\tau), \sigma$ and $\tau$ are ellipsoidal coordinates connected with the longitudinal coordinate $z$ and the distance $\rho$ from the ellipsoid symmetry axis by the equalities $\rho=\left[\left(1+\sigma^{2}\right)\left(1-\tau^{2}\right)\right]^{1 / 2}$ and $z=\sigma \tau$ (here, as a unit of length, it is taken half of the distance between foci of co-focal ellipses and hyperbole in the planes containing the symmetry axis). Also, it is expedient to use the variables $v=\arccos \tau$ and $u=\operatorname{ar} \sinh \sigma$, for which $z=\sinh u \cos v$ and $\rho=\cosh u \sin v$. The value $v=0 \quad(\tau=1)$ with real $\sigma$ corresponds to the symmetry axis $\rho=0$, the value $v=\pi / 2 \quad(\tau=0)$ with real $\sigma$ corresponds to the part of the plane $z=0$ external to the circle $\rho=1$, the value $u=0$ with $0 \leq v<\pi / 2$ corresponds to the part of the plane $z=0$ internal to the circle $\rho=1$. The cavity boundaries are characterized by some values, $u_{0}$ and $v_{0}\left(u_{0}>0,0<v_{0} \leq \pi / 2\right)$, and by the related values $\sigma_{0}=\sinh u_{0}$ and $\tau_{0}=\cos v_{0}$.

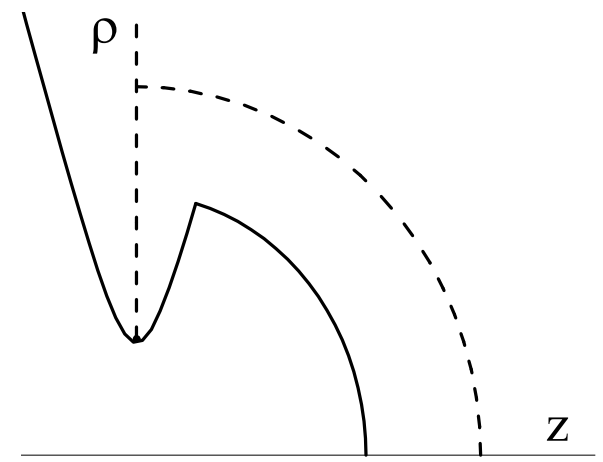

Cavities (oblate ellipsoids of revolution around $z$ axis); dashed boundaries correspond to the limit case $v_{0}=\pi / 2$

Writing the Laplace operator in ellipsoidal coordinates [5] and using the method of separation of variables, one comes to the equations,

$$
\begin{gathered}
(d / d \tau)\left[\left(1-\tau^{2}\right) d T / d \tau\right]+v(v+1) T=0, \\
(d / d \sigma)\left[\left(1+\sigma^{2}\right) d S / d \sigma\right]-v(v+1) S=0,
\end{gathered}
$$

in which $v$ does not depend on $\sigma$ and $\tau$. The second equation transforms to the first one with replacement of $S$ by $T$ and $\sigma$ by $\pm i \tau$, where $i$ is an imaginary unit. 
To write the solutions of the equations inside the cavity, one can use the Legendre functions [6],

$$
T(\tau)=\mathrm{P}_{v}(\tau), S(\sigma)=B \mathrm{Q}_{v}(i \sigma)+i(\pi / 2) A \mathrm{P}_{v}(i \sigma),
$$

where $A$ and $B$ are unknown constants, and $\mathrm{P}_{v}(w)$ and $\mathrm{Q}_{v}(w)$ (with the direct font for $\mathrm{P}$ and $\mathrm{Q}$ ) are functions of the complex variable $w$, defined on the interval $(-1,1)$ of real axis and analytically extended from there to the half-plane $\operatorname{Im} w>0$ [6, Section 3.4]. Below, it is used, also, the function $Q_{v}(w)$ (with italics for $Q$ ) other than $\mathrm{Q}_{v}(w)$ and decreasing when $w \rightarrow \infty$ [6, Section 3.2].

The boundary conditions have the form

$$
T\left(\tau_{0}\right)=0, S\left(\sigma_{0}\right)=0, S^{\prime}(0)=1,
$$

where a prime indicates a derivative. The last condition, neglecting the sign, corresponds to the unit dimensionless field strength (or to the unit dimensionless drift velocity) at the outlet of the cavity.

The first boundary condition gives the equation to find $v, \mathrm{P}_{v}\left(\cos v_{0}\right)=0$. In the cavity, the slowest decrease in field strength with depth (and hence the fastest exit from the cavity) corresponds to the smallest positive value of $v$. Assuming that $v$ denotes just such value, in the limit case $v_{0}=\pi / 2$ (when the wall of the cavity is infinitely thin, as it is shown in Figure), one gets $v=1$. The value of $v$ increases with $v_{0}$ decrease, and in the case $v_{0}<<1$ (when the cavity is a thin channel), taking into account the equality $\lim _{v \rightarrow \infty} \mathrm{P}_{v}(\cos (w / v))=\mathrm{J}_{0}(w)$, in which $\mathrm{J}$ denotes Bessel function, one comes to the relations $v \approx w_{0} / v_{0}>>1$, where $w_{0}$ is the first positive zero of the function $\mathrm{J}_{0}(w)$.

Using the equalities from [6] for derivatives at zero,

$\mathrm{P}_{v}^{\prime}(0)=2 \sin (\pi v / 2) \Gamma((v+2) / 2)\left[\pi^{1 / 2} \Gamma((v+1) / 2)\right]^{-1}$,

$\mathrm{Q}_{v}^{\prime}(0)=\pi^{1 / 2} \cos (\pi v / 2) \Gamma((v+2) / 2)[\Gamma((v+1) / 2)]^{-1}$,

where $\Gamma$ is gamma-function, for $A$ and $B$ one comes to the equalities

$$
\begin{gathered}
i \pi \mathrm{P}_{v}\left(i \sigma_{0}\right) /(2 B)=-\mathrm{Q}_{v}\left(i \sigma_{0}\right) / A= \\
=\pi^{1 / 2}[\Gamma((v+2) / 2) / \Gamma((v+1) / 2)] \times \\
\times\left[\mathrm{Q}_{v}\left(i \sigma_{0}\right) \sin (\pi v / 2)-\pi \mathrm{P}_{v}\left(i \sigma_{0}\right) \cos (\pi v / 2) / 2\right] .
\end{gathered}
$$

In particular, in the case $v_{0}=\pi / 2$ one gets $A=-2 / \pi, B=\sigma_{0} /\left(1+\sigma_{0} \operatorname{arctg} \sigma_{0}\right)$.

The distribution of dimensionless field strength (or dimensionless drift velocity) in the cavity along the axis of symmetry is described by a function $S^{\prime}(\sigma)$. For $0<\sigma<\sigma_{0}$ it may be written in the form

$$
S^{\prime}(\sigma)=\pi A W\left(\sigma, \sigma_{0}\right) /\left[2 \mathrm{Q}_{v}\left(i \sigma_{0}\right)\right]
$$

where $W\left(\sigma, \sigma_{0}\right)=\mathrm{P}_{v}\left(i \sigma_{0}\right) \mathrm{Q}_{v}^{\prime}(i \sigma)-\mathrm{P}_{v}^{\prime}(i \sigma) \mathrm{Q}_{v}\left(i \sigma_{0}\right)$.

For the dimensionless field strength (and ion drift velocity) in a deep $\left(\sigma_{0}>1\right)$ and sufficiently wide $\left(v_{0} \sim 1\right)$ cavity, using the equalities

$$
\begin{gathered}
Q_{v}(w)=\mathrm{Q}_{v}(w)-i \pi \mathrm{P}_{v}(w) / 2(\operatorname{Im} w>0), \\
\lim _{w \rightarrow i \infty}\left[\mathrm{P}_{v}(w)(2 w)^{-v}\right]=\pi^{-1 / 2} \Gamma((2 v+1) / 2) / \Gamma(v+1), \\
\lim _{w \rightarrow i \infty}\left[Q_{v}(w)(2 w)^{v+1}\right]=\pi^{1 / 2} \Gamma(v+1) / \Gamma((2 v+3) / 2),
\end{gathered}
$$

given in [6], at $\sigma_{0}>\sigma>>1$, one comes to the relation

$$
S^{\prime}(\sigma) \approx\left[v\left(\sigma / \sigma_{0}\right)^{(2 v+1) / 2}+(v+1)\left(\sigma_{0} / \sigma\right)^{(2 v+1) / 2}\right] \times
$$$$
\times \sigma_{0}^{-v}\left(\pi \sigma^{3} \sigma_{0}\right)^{-1 / 2}[(2 v+1) \Gamma((2 v+1) / 2)]^{-1} \Gamma^{2}((v+1) / 2),
$$

from which, in order of magnitude, it follows the relation $S^{\prime}(\sigma) \sim \sigma^{-v-2}$.

Integral $\int d \sigma / S^{\prime}(\sigma)$ over the interval $\left(0, \sigma_{0}\right)$ gives the time of ion exit from the cavity along the symmetry axis, which may be considered as the characteristic time $t_{\text {drift }}$ of ion exit from the cavity due to drift. In the case of a deep $\left(\sigma_{0}>>1\right)$ and sufficiently wide $\left(v_{0} \sim 1\right)$ cavity the integration gives the estimate

$$
t_{\text {drift }} \sim \sigma_{0}^{v+3} t_{\text {drl }} \text {, }
$$

where $t_{\mathrm{dr} 1}=h_{1} /\left(b E_{1}\right), h_{1}$ is half of the inter-focal distance (in co-focal ellipses and hyperbole), $E_{1}$ is field strength in the center of outlet, $b$ is ion mobility, and the exponent $v$ is the smallest positive root of the equation $\mathrm{P}_{v}\left(\cos v_{0}\right)=0$. For a thin channel $\left(v_{0}<<1\right)$, the relation $v>>1$ holds, and so, the field is almost absent and the characteristic time of ion exit is very large. In [4], cavities with field are called macropores, and cavities without field are called micropores.

In addition to the considered ion drift in a cavity with field, a significant role in the capacitive deionization process is played by ion drift under the field action in the space between electrodes. As a result of this drift, the concentration of corresponding ions near relevant electrodes increases or decreases, leading to increase of the diffusion ion fluxes into the electrode or away from it. In the case when the relationship $h_{\mathrm{g}} / h_{1} \gg \sigma_{0}^{v+3}$ takes place, the time of drift over the inter-electrode gap $h_{\mathrm{g}}$ is much greater than the time of drift into the cavity or from the cavity and, in this case, just the time of drift over the inter-electrode gap determines the time required to realize the deionization process.

If the flow is turbulent, through its excessive speed, or if the time of motion of the flow segment past the electrode is so small that most of ions do not have time to drift through the gap to the corresponding electrode, and on the further way to another gap between the pair of electrodes the flow mixes, then the efficiency of using of ion drift in the inter-electrode gap to achieve a high concentration of the corresponding ions near the relevant electrodes and to compensate the oppositely directed diffusion flux is low, as if the electrical resistance of the gap is large. It should be noted, however, that existence of cavities with field but without water flow (macropores) leads to some increase of ion drift contribution to the capacitive deionization process.

\section{DIFFUSION}

The processes of component diffusion into and out of the cavity for the density difference between the current and final state are described in the same way. To estimate the time during which the component concentration in the cavity changes significantly, it is expedient to proceed from the equation $\partial N / \partial t=\nabla^{2} N$, in which $N=\Omega(t) \Psi(\psi) V(v), \quad t \quad$ is dimensionless time, 
$v=\arccos \tau$ (as above), and $\psi=\operatorname{arccot} \sigma$, so that the values $\sigma=\{-\infty, 0,+\infty\}$ correspond to the values $\psi=\{\pi, \pi / 2,0\}$, respectively.

Writing the Laplace operator in ellipsoidal coordinates and using the method of separation of variables, one comes to the equations

$$
\begin{gathered}
d \Omega / d t=-\lambda \Omega, \\
d^{2} \Psi / d \psi^{2}+\left(\lambda / \sin ^{4} \psi-\mu / \sin ^{2} \psi\right) \Psi=0, \\
(d / d v)(\sin v d V / d v)+\left(\mu \sin v-\lambda \sin ^{3} v\right) V=0,
\end{gathered}
$$

in which the parameters $\lambda$ and $\mu$ do not depend on $t$, $\psi$, and $v$, but are interconnected.

The initial and boundary conditions have the form $V^{\prime}(0)=0, V^{\prime}\left(v_{0}\right)=0, \Psi^{\prime}\left(\psi_{0}\right)=0, \Psi(\pi / 2)=0$,

$$
\Omega(0)=1, V(0)=1, \Psi^{\prime}(\pi / 2)=-1,
$$

where $\psi_{0}=\operatorname{arccot} \sigma_{0}$. The conditions correspond to continuity of density at the symmetry axis, the absence of flows at the cavity boundary, zero density at the outlet, and the unit axial density gradient at the center of the outlet at the initial time.

The density evolution for any initial distribution can be given by the sum, $\sum_{\lambda \mu} A_{\lambda \mu} \Omega_{\lambda}(t) \Psi_{\lambda \mu}(\psi) V_{\lambda \mu}(v)$, where $\Omega_{\lambda}(t), \Psi_{\lambda \mu}(\psi)$, and $V_{\lambda \mu}(v)$ are the eigenfunctions of relevant problems, corresponding to the pairs of eigenvalues of the parameters $\lambda$ and $\mu$, and the coefficients $A_{\lambda \mu}$ depend on the initial distribution.

The equation for $\Omega(t)$ with the initial condition gives $\Omega(t)=\exp (-\lambda t)$. The distributions corresponding to eigenfunctions with larger $\lambda$ values decrease faster, and some time after the start the exit of the component from the cavity is described by a decrease (exponentially) of the distribution corresponding to eigenfunctions with the smallest $\lambda$ value.

In the case of a deep $\left(\sigma_{0}>>1\right.$, and, consequently, $\left.\psi_{0} \approx \sigma_{0}^{-1}<<1\right)$ cavity, the differential equations and the boundary conditions for $V(v)$ and $\Psi(\psi)$ imply the impossibility of existence of pairs of eigenvalues with small $\lambda$ but not small $\mu$. But if both $\lambda<<1$ and $\mu<<1$, then, from the equation and boundary conditions for $V(v)$, one comes to the relations

$$
\begin{gathered}
V(v) \approx 1, \\
(d / d v) V(v) \approx \\
\approx \tan (v / 2)\left[2 \sin ^{2}(v / 2)(2+\cos v) \lambda-3 \mu\right] / 3, \\
\mu \approx 2 \sin ^{2}\left(v_{0} / 2\right)\left(2+\cos v_{0}\right) \lambda / 3,
\end{gathered}
$$

and then, from the equation and boundary conditions for $\Psi(\psi)$, in the interval $\psi_{0}<\psi<\pi / 2$, at $\psi \sim 1$, one gets $d \Psi / d \psi \approx-1$ and $\Psi+\psi \approx \pi / 2$, and at $\psi<<1$, one gets $d^{2} \Psi / d \psi^{2} \approx-\lambda \Psi / \psi^{4}, \quad \Psi \approx \pi / 2$, and $d \Psi / d \psi \approx-\pi \lambda\left(\psi_{0}^{-3}-\psi^{-3}\right) / 6$, and to reconcile the relations for $d \Psi / d \psi$ at $\psi$ between $\psi \sim 1$ and $\psi<<1$, the relation $\lambda \approx 6 \psi_{0}^{3} / \pi$ should be held.
That is, the characteristic time of diffusion of the component significant part from a deep cavity is given by the relationship

$$
t_{\text {diffus }} \sim \sigma_{0}^{3} t_{\mathrm{dfl}},
$$

where $t_{\mathrm{df} 1}=h_{1}^{2} / D, D$ is diffusion coefficient, and so, $t_{\mathrm{df1}}$ is relevant time for a shallow cavity with the characteristic size $h_{1}$. It should be emphasized that the characteristic time of diffusion exit from a cavity is almost independent on the cavity width. And it is natural to assume that for thin channels, possibly curved and multi-connected, their characteristic diffusion emptying time is determined by the maximum, over the points in the given channel, of the path length (inside the channel) from the current point to the nearest outlet.

\section{RELATIVE CONTRIBUTION OF DRIFT AND DIFFUSION}

Using the equality $\sigma_{0}=h_{0} / h_{1}$, where $h_{0}$ is the cavity depth (the distance, along the symmetry axis, from the boundary of the cavity to the outlet), for the characteristic time of drift and diffusion exit, in the case $\sigma_{0}>>1$, one comes to the relationships $t_{\text {drift }} \sim\left(h_{0} / h_{1}\right)^{v+3} h_{1} /\left(b E_{1}\right)$ and $t_{\text {diffus }} \sim\left(h_{0} / h_{1}\right)^{3} h_{1}^{2} / D$, respectively. The drift time increases, with the cavity relative depth $\sigma_{0}$ increase, faster than the diffusion time, through the decrease of the field strength with depth. Taking into account Einstein's relationship between the mobility and diffusion coefficient, $D=b U_{\text {lab }}$, where $U_{\text {lab }}$ is the average ion energy under the experimental conditions divided by the elementary charge, one can obtain the relationships,

$$
\begin{aligned}
t_{\text {drift }} / t_{\text {diffus }} & \sim\left(h_{0} / h_{1}\right)^{v} t_{\mathrm{dr} 1} / t_{\mathrm{dfl} 1}, \\
t_{\mathrm{dr} 1} / t_{\mathrm{df} 1} & \sim U_{\mathrm{lab}} h_{\mathrm{g}} /\left(U_{\mathrm{g}} h_{1}\right), \\
t_{\mathrm{drift}} / t_{\mathrm{diffus}} & \sim\left(h_{0} / h_{1}\right)^{v} U_{\mathrm{lab}} h_{\mathrm{g}} /\left(U_{\mathrm{g}} h_{1}\right),
\end{aligned}
$$

where $U_{\mathrm{g}}=E_{1} h_{\mathrm{g}}$ (the applied voltage that corresponds to the field strength $E_{1}$ for the distance $h_{\mathrm{g}}$ between electrodes).

For the experiments performed at room temperature with use of voltage of the order of $1 \mathrm{~V}$, one can put $U_{\text {lab }} / U_{\mathrm{g}} \sim 0.03$. For the characteristic distance $h_{\mathrm{g}}$ between electrodes of the order of $1 \mathrm{~mm}$, in the tested device, the relation $h_{1} / h_{\mathrm{g}} \leq 0.03$ takes place for the outlet size $h_{1} \leq 30 \mu \mathrm{m}$, and then, as the cavity is deep $\left(h_{0} / h_{1}>>1\right)$, the time of drift exit from the cavity significantly exceeds the time of diffusion exit. The diffusion exit time does not depend on the applied voltage and on the distance between the electrodes. For the diffusion coefficient, at the room temperature, one can take the value of the order of $10^{-5} \mathrm{~cm}^{2} / \mathrm{s}[7, \mathrm{p} .30]$. Then, for $h_{1} \sim 10 \mathrm{~nm}$, one gets $t_{\mathrm{dfl}} \sim 10^{-7} \mathrm{~s}$, and the value of $t_{\text {diffus }} \sim 1000 \mathrm{~s}$ (obtained in the experiment [1]) corresponds to the relative depth of the cavity $h_{0} / h_{1} \sim 2000$.

The shape of real cavities is not so simple as one considered in the present study. In particular, the entrance to a cavity may be located on the boundary of 
another cavity, and if the entrance to a deep cavity is located on the boundary of a shallow wide cavity then the shallow wide cavity may be filled, mainly, due to drift, and the deep cavity is filled, mainly, due to diffusion.

\section{CONCLUSIONS}

To estimate the time required to reach equilibrium in the process of water capacitive deionization, the drift under the action of an electric field and diffusion of ions in a cavity having the shape of oblate ellipsoid of revolution are considered. Such shape makes it possible to solve the problems by the method of separation of variables. For a deep cavity, using Einstein's relationship between the diffusion coefficient and the ion mobility, estimates are obtained (in order of magnitude) for the time of the cavity filling with ions (or emptying of ions) by drift and diffusion. These estimates, along with the relative depth of the cavity, contain the ratio of the cavity outlet size to the distance between electrodes and the ratio of temperature to the applied voltage. From the estimates, it follows that in the performed experiments with the device for the water capacitive deionization, the filling of the carbon electrode with ions (and its emptying from ions) was mainly due to diffusion.

\section{REFERENCES}

1. V.I. Golota, L.M. Zavada, D.V. Kudin, S.V. Rodionov. Development of technology for water capacitive deionization // Journal of Kharkiv $\mathrm{Na}$ tional University, physical series "Nuclei, Particles, Fields”. 2012, issue 4(56), № 1025, p. 98-101.

2. V.I. Golota, D.V. Kudin, S.V. Rodionov, S.Yu. Gorbenko, L.M. Zavada, D.V. Moshinskii. Degradation of sorption properties of electrode material of device for water capacitive deionization // Scientific works of Kharkiv National Air Force University. 2013, № 1(34), p. 153-156.

3. V.I. Golota, S.Yu. Gorbenko, M.A. Yegorov, L.M. Zavada, D.V. Kudin, D.V. Moshinskii, S.V. Rodionov. De-nitrification of water solutions by capacitive deionization method // Scientific works of Kharkiv National Air Force University. 2013, № 2(35), p. 166-168.

4. R. Zhao. Theory and operation of capacitive deionization systems. Dissertation. Wageningen University, Netherlands, 2013.

5. G.A. Korn, T.M. Korn. Mathematical handbook. McGraw-Hill Book Company, 1968.

6. H. Bateman, A. Erdelyi. Higher transcendental functions. McGraw-Hill Book Company, 1963.

7. A.I. Levin. Theoretical foundations of electrochemistry. Moscow, 1963.

Article received 07.06.2021

\section{ВКЛАД ДРЕЙФА И ДИФФУЗИИ В ЕМКОСТНУЮ ДЕИОНИЗАЦИЮ ВОДЫ}

\section{Д.В. Кудин, В.Н. Остроуико, А.В. Пащенко, С.В. Родионов, М.А. Егоров, Л.М. Завада}

Рассмотрены дрейф и диффузия ионов в полости, которая имеет форму сплюснутого эллипсоида вращения. Полученное приближенное соотношение, между временами дрейфового и диффузионного заполнения глубокой полости ионами, содержит приложенное напряжение и отношение размеров полости к расстоянию между электродами и указывает, что в выполненных экспериментах с устройством для емкостной деионизации воды заполнение электродов ионами осуществлялось, в основном, через диффузию.

\section{ВНЕСОК ДРЕЙФУ ТА ДИФУЗІЇ В ЄМНІСНУ ДЕІОНІЗАЦІЮ ВОДИ}

\section{Д.В. Кудін, В.М. Остроуико, А.В. Пащенко, С.В. Родіонов, М.О. Сгоров, Л.М. Завада}

Розглянуто дрейф та дифузію іонів у порожнині, яка має форму сплюснутого еліпсоїду обертання. Отримане наближене співвідношення між часом дрейфового та дифузійного заповнення глибокої порожнини іонами містить докладену напругу та відношення розмірів порожнини до відстані між електродами та вказує, що у виконаних експериментах з пристроєм для ємнісної деіонізації води заповнення електродів іонами здійснювалося, переважно, через дифузію. 